\title{
The Efficiency of Strontium-90 Desorption Using Iron (III) Solutions in the Decontamination Process of Radioactive Soils
}

\author{
Olga Cheremisina ${ }^{1}$, Vasiliy Sergeev ${ }^{1 *}$, Varvara Alabusheva ${ }^{1}$, \\ Alexander Fedorov ${ }^{1}$, Alexandra lliyna ${ }^{1}$ \\ 1 Department of Physical Chemistry, Saint Petersburg Mining University, Saint-Petersburg, 21 Line 2, 199106, \\ Russian Federation \\ * Corresponding author's e-mail: sergeev.spmi@yandex.ru
}

\begin{abstract}
The paper presents the investigation on the estimated efficiency of iron (III) chloride solutions in the decontamination process of radioactive soils with ${ }^{90} \mathrm{Sr}$, according to kinetic and thermodynamic characteristics of the desorption process. The specific ${ }^{90} \mathrm{Sr}$ radioactivity of soil samples was $(3.9 \pm 0.3) \cdot 10^{4} \mathrm{~Bq} \cdot \mathrm{g}$. The adsorption isotherms of $\mathrm{Sr}^{2+}$ and $\mathrm{Fe}^{3+}$ are described with the Langmuir equation. The values of Gibbs energy $\mathrm{G}_{298}^{0}=-4.65 \mathrm{~kJ} \cdot \mathrm{mol}^{-1}$ and equilibrium ion exchange constant $\mathrm{K}_{\mathrm{eq}}=6.5$ confirm the hypothesis of strontium removal from soils with iron (III) cations. The effectiveness of the method is substantiated by experimental and calculated results of this study samples of radioactive soils are deactivated in $90 \%$ after 9.5 hours, whereas the kinetic constant is $6.77 \cdot 10 \mathrm{~s}^{-1}$. The suggested method of soil cleanup with $0.2 \mathrm{M} \mathrm{Fe}^{3+}$ solutions is optimal and complies with the environmental requirements.
\end{abstract}

Keywords: decontamination of radionuclides, thermodynamic and kinetics investigations, desorption of strontium-90, iron (III) chloride.

\section{INTRODUCTION}

Radioactive isotopes of heavy metals are considered to be particularly dangerous matter which is produced in the course of anthropogenic activities, industrial accidents and nuclear tests. Strontium-90 isotope is mainly fixed on the surface of clay minerals [Bobovnikova 1990]. Radionuclides undergo physicochemical reactions on the border between solid and liquid phases in soils, where strontium is found in different forms. There are cations of radionuclides in the soil solution and cations which are fixed in solid (non-exchangeable). Fixation of exchangeable form and remobilization of fixed radionuclides are caused by cations diffusion in solid particles [Bulgakov 1998, Bondarenko and Kononenko 2001]. The majority of water-soluble ${ }^{90} \mathrm{Sr}(76 \%)$ occurs in cation forms [Martyushov et al. 1995].

The authors Ningping and Mason [2001] propose strontium-free ground water for $\mathrm{Sr}$ (II) removal from silica colloids and Ca-montmoril- lonites. The desorption from montmorillonites is a time-consuming and ineffective process - the amount of recovered strontium is $16.5 \%$ after 90 days. Desorption in the study [Martyushov et al. 1995] was executed with different concentrations of $\mathrm{HCl}$ and $\mathrm{HNO}_{3}$. The most effective outcome was achieved with $0.1 \mathrm{M}$ solutions $-83 \%$ and $82 \%$ for $\mathrm{HCl}$ and $\mathrm{HNO}_{3}$, respectively. However, strong acids are too expensive and they form acidic soils which are not applicable.

The review of the literature on the ${ }^{90} \mathrm{Sr}$ desorption process indicates that there is a need to detect an eluent for radioactive soils recultivation which is safe and provides effective desorption parameters.

It was proposed that ion exchange of strontium with high complex formation properties will promote the extraction of radionuclides from soils. Cations of $\mathrm{Fe}^{3+}$ are characterized by a high charge and a small radius. Due to the high ionic potential, which is equal to $\mathrm{z} / \mathrm{r}, \mathrm{Fe}^{3+}$ displaces other cations from mineral surface, including ${ }^{137} \mathrm{Cs}$ and ${ }^{90} \mathrm{Sr}$. 
Therefore, it was suggested to apply iron (III) chloride solutions with ammonium chloride (for $\mathrm{pH}$ stabilization) for soils decontamination.

The aim of this investigation was to estimate the efficiency of iron (III) chloride solutions in the decontamination process of radioactive soils with ${ }^{90} \mathrm{Sr}$ according to kinetic and thermodynamic characteristics of the desorption process.

\section{MATERIALS AND METODS}

The process of sorption was performed on samples using water solutions with the specific radioactivity of $10^{-5} \mathrm{Ci} \cdot \mathrm{dm}^{-3}$. The process was carried out with the limited value method. The sample weight was brought into contact with the ${ }^{90} \mathrm{Sr}$ solution, interblended roundly with a churn over two weeks in order to obtain a stable solution. The solid phase was separated from the liquid phase and washed with distilled water. The specific ${ }^{90} \mathrm{Sr}$ radioactivity of soil samples was $(3.9 \pm 0.3) \cdot 10^{4} \mathrm{~Bq} \cdot \mathrm{g}^{-1}$.

The ${ }^{90} \mathrm{Sr}$ desorption was applied dynamically. It was chosen to apply $0.02 \mathrm{~mol} \cdot \mathrm{dm}^{-3}$ iron (III) chloride as an eluent solution. The process was held in a $5 \mathrm{~cm}$ height glass column with the cross-sectional area of $0.7 \mathrm{~cm}^{2}$ and the interstitial volume of $3 \mathrm{~cm}^{2}$. The underside of the column was filled with glass fiber and a Sr-adsorbed soil sample of $2 \mathrm{~g}$ weight above it. The desorption agent was carried through the solid structure with the $9 \cdot 10^{-4} \mathrm{~m} \cdot \mathrm{s}^{-1}$ rapidity. After $3 \mathrm{~cm}^{3}$ of the eluent passed the column, 5 and $10 \mathrm{ml}$ portions were collected and their ${ }^{90} \mathrm{Sr}$ radioactivity was analyzed. If there are both ${ }^{90} \mathrm{Sr}$ and ${ }^{137} \mathrm{Cs}$ radionuclides in soils, it is necessary to supplement ammonium chloride as a cesium carrier.

Real contaminated soil patterns were collected in the area which is 15 away from the 4th plant unit of the Chernobyl Electric Power Station.

\section{RESULTS AND DISCUSSION}

The adsorption isotherms of $\mathrm{Sr} 2+$ and $\mathrm{Fe} 3+$ are described with the Langmuir equation and shown in Figure 1, where $\nabla \infty$ is equilibrium concentration of the cations, $g$ - the activity factor and $\mathrm{DS} / \mathrm{L}$ is the distribution constant between the solid and liquid phases.

Figure 2 shows the linear dependence between the inverse of sorption and concentration. The equations are $\frac{1}{\Gamma}=0.1075 \frac{1}{\mathrm{C}}+26.588$ and $\frac{1}{\Gamma}=0.0512 \frac{1}{\mathrm{C}}+42.18$ for strontium and iron (III), respectively. This result is in accordance with the study [Chirkst et al. 1994, Chirkst et al. 2003], where effectiveness of the Langmuir equation is described for cesium cations sorption on a variety of minerals.

The absolute term of the Langmuir equation is equal to the inverse of the limit value of sorption, which is $0.034 \mathrm{~mol} \cdot \mathrm{kg}^{-1}$ for $\mathrm{Sr}^{2+}$ and 0.024 $\mathrm{mol} \cdot \mathrm{kg}^{-1}$ for $\mathrm{Fe}^{3+}$. Slope ratios were used to determine the adsorption thermodynamic equilibrium ratios of strontium and iron on clay minerals which are 294 and 731, respectively.

The distribution coefficient of strontium between the solid and liquid phases depends on strontium $(2+)$ concentration in equilibrium solution and coverage ratio of the adsorbent:
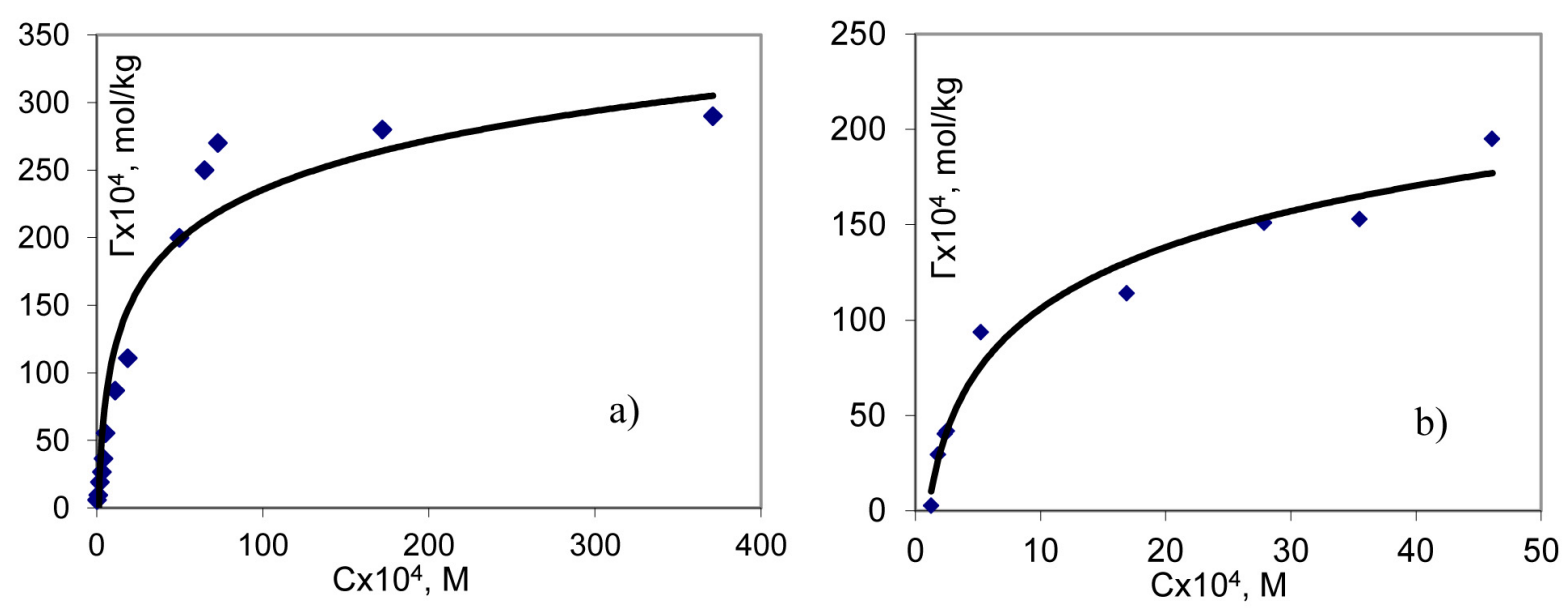

Figure 1. The sorption isotherms of strontium (a) and iron (3+) cations (b) on clay minerals 
Table 1. Characteristics of $\mathrm{Sr}^{2+}$ and $\mathrm{Fe}^{3+}$ distribution between the solution and clay samples

\begin{tabular}{|c|c|c|c|c|c|}
\hline \multicolumn{3}{|c|}{$\mathrm{Sr}^{2+}$} & \multicolumn{3}{|c|}{$\mathrm{Fe}^{3+}$} \\
\hline $\mathrm{C}_{\infty} \cdot 10^{4}, \mathrm{~mol} \cdot \mathrm{dm}^{-3}$ & $\gamma_{\mathrm{Sr}}^{2+}$ & $D_{S / L}$ & $\mathrm{C}_{\infty} \cdot 10^{4}, \mathrm{~mol} \cdot \mathrm{dm}^{-3}$ & $\gamma_{\mathrm{Fe}}^{3+}$ & $D_{S / L}$ \\
\hline 0.42 & 0.92 & 15.0 & 1.28 & 0.73 & 2.8 \\
\hline 1.05 & 0.89 & 10.2 & 1.84 & 0.58 & 27.5 \\
\hline 2.08 & 0.85 & 10.8 & 2.38 & 0.54 & 31.3 \\
\hline 3.33 & 0.83 & 9.7 & 2.53 & 0.53 & 31.1 \\
\hline 4.36 & 0.80 & 10.4 & 5.24 & 0.41 & 43.6 \\
\hline 5.55 & 0.80 & 10.0 & 16.9 & 0.30 & 22.5 \\
\hline 11.3 & 0.72 & 10.7 & 27.9 & 0.23 & 23.5 \\
\hline 18.9 & 0.67 & 9.8 & 35.5 & 0.20 & 27.4 \\
\hline 50 & 0.56 & 7.2 & 46.1 & 0.18 & 18.5 \\
\hline 65 & 0.52 & 7.4 & & & \\
\hline 73 & 0.51 & 7.3 & & & \\
\hline 172 & 0.44 & 3.7 & & & \\
\hline 371 & 0.34 & 0.23 & & & \\
\hline
\end{tabular}
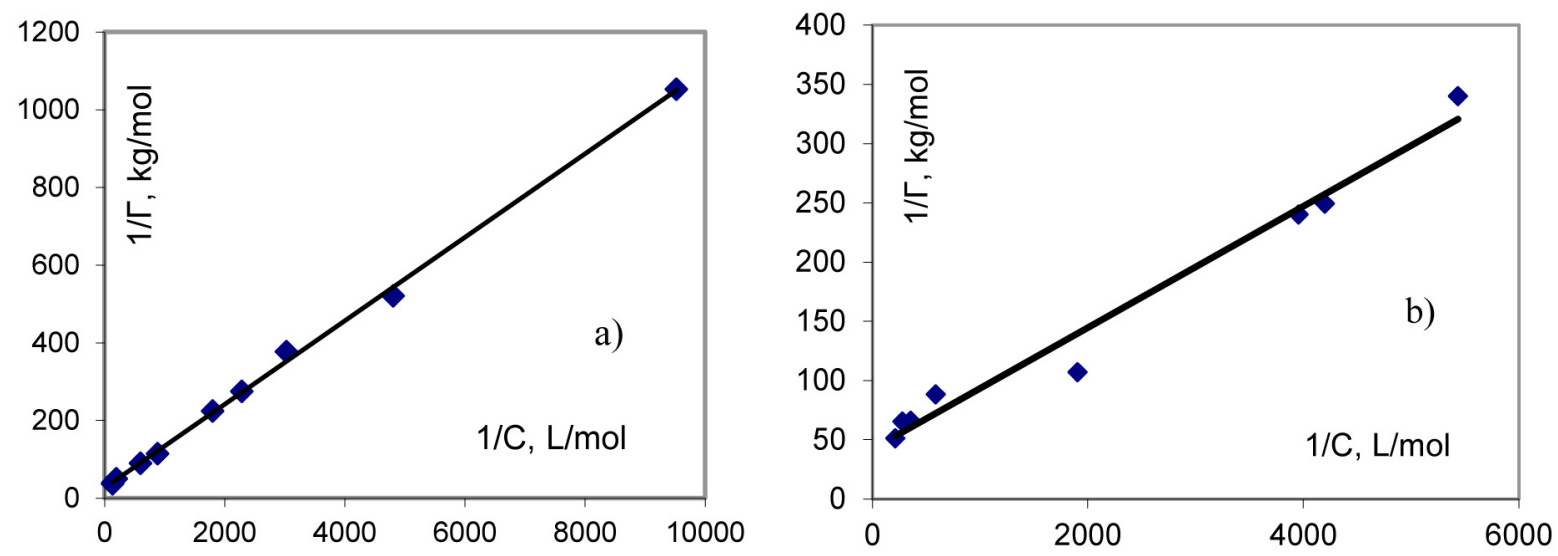

Figure 2. Linear form of the sorption isotherm for strontium (2+) (a) and iron (b) on clay minerals

$$
D_{\mathrm{T} / \text { ж }}=\frac{\Gamma_{\infty} \mathrm{K}}{\gamma_{\mathrm{Sr}^{2}+}\left(1+K \mathrm{C}_{\infty}\right)}
$$

However, limit dilution brings about the value $\operatorname{ofD}_{\mathrm{S} / \mathrm{L}}=\Gamma_{\infty} \mathrm{K}=10.0$ which is the same as the experimental result (Table 1). For the $\mathrm{Sr}^{2+}+_{\text {aq }} \Leftrightarrow \mathrm{Sr}^{2+}$ адс equilibrium, which characterizes the sorption ability of a strontium cation, the value of Gibbs energy is $\Delta G^{0_{298}}=-\mathrm{RT} \ln D_{S / L}=-5.7 \mathrm{~kJ} / \mathrm{mol}$. This value illustrates rising of the sorption ability in response to hydroxonium cations transition with strontium cations due to increase of the charge.

According to the study [Thermodynamic constants... 1981], under the condition of $\Delta_{f} G^{0298}\left(\mathrm{Sr}^{2+{ }_{\mathrm{aq}}}\right)=-563.9 \mathrm{~kJ} / \mathrm{mol}$, the value of Gibbs energy for adsorbed cation formation is $\Delta_{f} G^{0}{ }_{298}=-569.6 \mathrm{~kJ} / \mathrm{mol}$.
The following equations are defined with the distribution coefficient of $\mathrm{Fe}^{3+}$ and the Langmuir constant:

$$
\begin{gathered}
\mathrm{Fe}^{3+}{ }_{\text {aq }} \Leftrightarrow \mathrm{Fe}^{3+}{ }_{\text {ads }} \\
\mathrm{Fe}(\mathrm{OH})^{2+}{ }_{\text {aq }} \Leftrightarrow \mathrm{Fe}(\mathrm{OH})^{2+}{ }_{\text {ads }} \\
\mathrm{Fe}(\mathrm{OH})_{2}{ }^{+} \text {aq }
\end{gathered}
$$

The main forms of iron $(3+)$ in solutions with the value of $\mathrm{pH} 3.1$ are taken into account with corresponding thermodynamic characteristics. The sorption of iron (III) polymeric forms is neglected. The summary of the equations (5)-(7) describes the adsorption process of iron (III) with $\mathrm{m}, \mathrm{n}$ and $\mathrm{p}$ coefficients:

$$
\frac{n}{m}=\frac{\left[\mathrm{Fe}(\mathrm{OH})^{2+}\right]}{\left[\mathrm{Fe}^{3+}\right]}=\frac{K_{h, 1}}{\left[H^{+}\right]}
$$




$$
\begin{gathered}
\frac{p}{n}=\frac{\left[\mathrm{Fe}(\mathrm{OH})_{2^{+}}\right]}{\left[\mathrm{Fe}(\mathrm{OH})^{2+}\right]}=\frac{K_{h, 2}}{\left[H^{+}\right]} \\
m+n+p=1
\end{gathered}
$$

Hydrolysis constants of iron (3+) are $\mathrm{K}_{\mathrm{h}, 1}=6.74 \cdot 10^{-3}$ and [9]. Hydroxonium cations concentration is found due to $\mathrm{pH}=3.1$. Consequently, $\mathrm{m}=0.024 . \mathrm{n}=0.20$ and $\mathrm{p}=0.776$. The summary equation of the iron (III) adsorption process is:

$$
\begin{aligned}
& 0.024 \mathrm{Fe}^{3+}{ }_{\text {aq }}+0.2 \mathrm{Fe}(\mathrm{OH})^{2+}{ }_{\text {aq }}+ \\
& +0.776 \mathrm{Fe}(\mathrm{OH})_{2}{ }_{\text {aq }} \Leftrightarrow \\
& \Leftrightarrow 0.024 \cdot \mathrm{Fe}^{3+}{ }_{\text {ads }}+0.2 \mathrm{Fe}(\mathrm{OH})^{2+}{ }_{\text {ads }}+ \\
& +0.776 \mathrm{Fe}(\mathrm{OH})_{2}{ }^{+} \text {ads }
\end{aligned}
$$

Using the summary distribution coefficient, it is possible to determine the Gibbs energy for the reaction (8): $\Delta_{(8)} \mathrm{G}_{298}^{0}=\Delta \mathrm{RT} \ln \mathrm{D}_{\mathrm{S} / \mathrm{L}}=-8.2 \pm 0.3$ $\mathrm{kJ} \cdot \mathrm{mol}^{-1}$.

In order to calculate the equilibrium constants for (2)-(4), it is necessary to make a series of operations.

$$
\begin{aligned}
& \Delta_{(8)} \mathrm{G}_{298}^{0}=\mathrm{m} \Delta_{(2)} \mathrm{G}^{0}{ }_{298}+ \\
& +\mathrm{n} \Delta_{(3)} \mathrm{G}^{0}{ }_{298}+\mathrm{p} \Delta_{(4)} \mathrm{G}^{0}{ }_{298} . \\
& \text { Then: } \mathrm{D}=\mathrm{D}_{1}{ }^{\mathrm{m}} \cdot \mathrm{D}_{2}{ }^{\mathrm{n}} \cdot \mathrm{D}_{3}{ }^{\mathrm{p}},
\end{aligned}
$$

where: $D$ is the experimental summarized distribution coefficient of iron (III), $\mathrm{D}_{\mathrm{n}}$ - partial distribution coefficients of different iron forms for the equations (2)-(4), and their values are:

$$
\begin{gathered}
D_{1}=\frac{\left[\mathrm{Fe}^{3+{ }_{\mathrm{ads}}}\right]}{\left[\mathrm{Fe}^{3+}{ }_{\mathrm{aq}}\right]} \\
D_{2}=\frac{\left[\mathrm{Fe}(\mathrm{OH})^{2+_{\mathrm{ads}}}\right]}{\left[\mathrm{Fe}(\mathrm{OH})^{\left.2+{ }_{\mathrm{aq}}\right]}\right.} \\
D_{3}=\frac{\left[\mathrm{Fe}(\mathrm{OH})_{2_{\mathrm{ads}}^{+}}\right]}{\left[\mathrm{Fe}(\mathrm{OH})_{2_{\mathrm{aq}}^{+}}\right]} \\
D=\frac{\left[\mathrm{Fe}(\mathrm{OH})^{2+}{ }_{\mathrm{ads}}\right]+\left[\mathrm{Fe}(\mathrm{OH})_{2_{\text {ads }}^{+}}\right]}{\mathrm{C}}
\end{gathered}
$$

The sorption of $\mathrm{Fe}^{3+}$ ions is neglected in (14) due to their small concentration. Calculating (11)-(14), the values of $\mathrm{D}_{2}$ and $\mathrm{D}_{3}$ are:

$$
\begin{aligned}
& D_{3}=\frac{D \cdot C-\left[\mathrm{Fe}(\mathrm{OH})^{2+}{ }_{\mathrm{ads}}\right]}{\left[\mathrm{Fe}(\mathrm{OH})_{2_{\mathrm{aq}}^{+}}\right]} \\
& =\frac{D \cdot C-K_{2} \cdot\left[\mathrm{Fe}(\mathrm{OH})^{2+{ }_{\mathrm{aq}}}\right]}{\left[\mathrm{Fe}(\mathrm{OH})_{2_{\mathrm{aq}}^{+}}\right]}
\end{aligned}
$$

The values $\mathrm{D}=27,\left[\mathrm{Fe}(\mathrm{OH})^{2+\mathrm{aq}}\right]=0.776 \mathrm{C}$, $\left[\mathrm{Fe}(\mathrm{OH})_{2_{\text {aq }}^{+}}\right]=0.2 \mathrm{C}$ are substituted into the equation (15). Calculating together the equations (11) and (14), where the exchange coupling constant is approximately 1 (and $\mathrm{D}_{1} \approx \mathrm{D}_{2}{ }^{1.5}, \mathrm{D}_{2}$ $\approx \mathrm{D}_{3}^{2}$ и $\mathrm{D}_{1} \approx \mathrm{D}_{2} \cdot \mathrm{D}_{3}$ ), the distribution constants are $\mathrm{D}_{1}=1200, \mathrm{D}_{2}=60$ and $\mathrm{D}_{3}=20$. Then $\Delta_{(2)} \mathrm{G}_{298}^{0}=$ $-17.6 \mathrm{~kJ} \cdot \mathrm{mol}^{-1}, \Delta_{(3)} \mathrm{G}_{298}^{0}=-10.2 \mathrm{~kJ} \cdot \mathrm{mol}^{-1}$ and $\Delta_{(4)}$ $\mathrm{G}^{0}{ }_{298}=-7.4 \mathrm{~kJ} \cdot \mathrm{mol}^{-1}$. Table 2 shows the calculated Gibbs energy of adsorbed iron ( $3+)$ cations formation and sorption equilibrium.

Furthermore, there are three exchange reactions:

$$
\begin{aligned}
& 13 \mathrm{Fe}^{3++_{\mathrm{aq}}}+12 \mathrm{Sr}^{2++_{\mathrm{ads}}} \Leftrightarrow \\
& \Leftrightarrow 13 \mathrm{Fe}^{3+}+_{\mathrm{ads}}+12 \mathrm{Sr}^{2++_{\mathrm{aq}}} \\
& \Delta_{(16)} \mathrm{G}^{0}{ }_{298}=-3.02 \mathrm{~kJ} \cdot \text { equiv }^{-1} \\
& \mathrm{~K}_{(16)}=3.4 .
\end{aligned}
$$

$$
\begin{aligned}
& 12 \mathrm{Fe}(\mathrm{OH})^{2+}{ }_{\mathrm{aq}}+12 \mathrm{Sr}^{2+}+_{\mathrm{ads}} \Leftrightarrow \\
& \Leftrightarrow 12 \mathrm{Fe}(\mathrm{OH})^{2++_{\mathrm{ads}}}+12 \mathrm{Sr}^{2+}{ }_{\mathrm{aq}} \\
& \Delta_{(17)} \mathrm{G}^{0}{ }_{298}=-2.25 \mathrm{~kJ} \cdot \text { equiv }^{-1} ; \\
& \mathrm{K}_{(17)}=2.5 .
\end{aligned}
$$

$$
\begin{aligned}
& \mathrm{Fe}(\mathrm{OH})_{2_{\mathrm{aq}}^{+}}+12 \mathrm{Sr}^{2+}{ }_{\mathrm{ads}} \Leftrightarrow \\
& \Leftrightarrow \mathrm{Fe}(\mathrm{OH})_{2_{\mathrm{ads}}^{+}}+12 \mathrm{Sr}^{2+}{ }_{\mathrm{aq}} \\
& \Delta_{(18)} \mathrm{G}_{298}^{0}=-4.55 \mathrm{~kJ} \cdot \text { equiv }^{-1} \\
& \mathrm{~K}_{(18)}=6.3 .
\end{aligned}
$$

The Gibbs energy for the summary ion exchange reaction with strontium is:

$\Delta_{\Sigma} \mathrm{G}^{0}{ }_{298}=0.072 \Delta_{(16)} \mathrm{G}^{0}{ }_{298}+0.4 \Delta_{(17)} \mathrm{G}^{0}{ }_{298}+0.776 \Delta_{(18)}$ $\mathrm{G}^{0}{ }_{298}=-4.65 \mathrm{~kJ} \cdot \mathrm{mol}^{-1}$.

Consequently, the total ion exchange equilibrium constant is 6.5 . It means that strontium cations will expel from clay minerals after a leaching operation with iron (III) solutions.

Iron (III) chloride solutions were used for strontium desorption from clay minerals. According to the experimental data (Figure 3), the kinetic coefficient of ${ }^{90} \mathrm{Sr}$ sorption on modelling samples is $2.9 \cdot 10^{-4} \mathrm{~s}^{-1}$ through the Wigner-Polanyi equation. The initial specific ${ }^{90} \mathrm{Sr}$ radioac- 
Table 2. Thermodynamic characteristics of iron and strontium cations adsorption on clay minerals

\begin{tabular}{|c|c|c|c|c|}
\hline Reaction & $\begin{array}{c}\Delta_{f} G^{0}{ }_{298}\left(\mathrm{Kat}^{z+}{ }_{q}\right) \\
\mathrm{kJ} \cdot \mathrm{mol}^{-1}[147]\end{array}$ & $\begin{array}{c}\Delta_{f} G^{0}{ }_{298}\left(\mathrm{Kat}^{z+}{ }_{a d s}\right) \\
\mathrm{kJ} \cdot \mathrm{mol}^{-1}\end{array}$ & $\begin{array}{l}\Delta_{f} G^{0}{ }_{298} \\
\mathrm{~kJ} \cdot \mathrm{mol}^{-1}\end{array}$ & $\mathrm{~K}_{\mathrm{eq}}$ \\
\hline $\mathrm{Fe}^{3+}{ }_{\mathrm{aq}} \leftrightarrow \mathrm{Fe}^{3+}{ }_{\text {ads }}$ & -4.52 & -22.1 & -17.6 & 1200 \\
\hline $\mathrm{Fe}(\mathrm{OH})^{2+}{ }_{\mathrm{aq}} \leftrightarrow \mathrm{Fe}(\mathrm{OH})^{2+}{ }_{\mathrm{ads}}$ & -229.37 & -239.6 & -10.2 & 60 \\
\hline $\mathrm{Fe}(\mathrm{OH})_{2}^{+}$aq $\leftrightarrow \mathrm{Fe}(\mathrm{OH})_{2}^{+}$ads & -452.29 & -459.7 & -7.4 & 20 \\
\hline $\mathrm{Sr}^{2+}{ }_{\mathrm{aq}} \leftrightarrow \mathrm{Sr}^{2+}{ }_{\text {ads }}$ & -563.9 & -569.6 & -5.7 & 10 \\
\hline
\end{tabular}

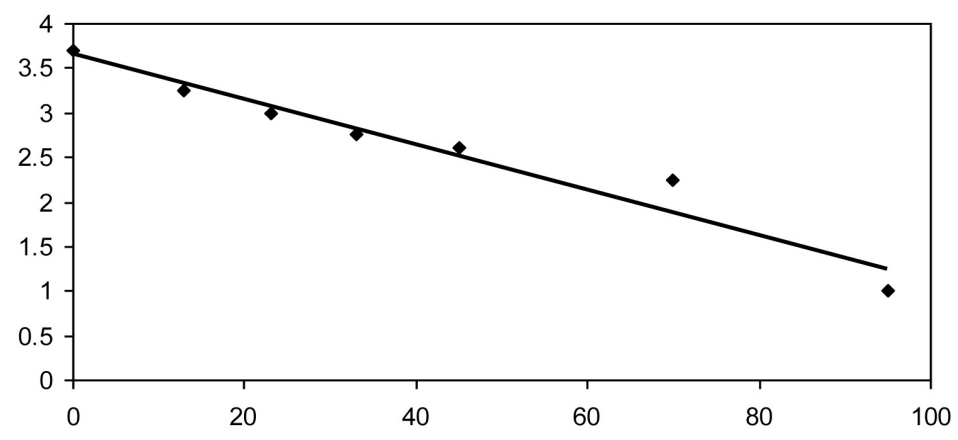

Figure 3. Desorption kinetics of ${ }^{90} \mathrm{Sr}$ from modelling samples

tivity of soils is $(3.9 \pm 0.3) \cdot 10^{4} \mathrm{~Bq} \cdot \mathrm{g}^{-1}$. As a result, the time required to achieve $90 \%$ desorption is approximately 2.2 hours.

After the process of ablution, the value of initial specific ${ }^{90} \mathrm{Sr}$ radioactivity changed from $7.23 \cdot 10^{2} \mathrm{~Bq} \cdot \mathrm{g}^{-1}$ to $1.87 \cdot 10^{2} \mathrm{~Bq} \cdot \mathrm{g}^{-1}$. As a consequence, the extent of desorption is $75 \pm 5 \%$. The kinetic constant for natural soil samples is $6.77 \cdot 10$ $\mathrm{c}^{-1}$ and the period of $90 \%$ desorption is 9.5 hours. Accordingly, the kinetic constant of real samples sorption is 5 times bigger than modelling samples.

\section{CONCLUSIONS}

The values of Gibbs energy $\mathrm{G}_{298}^{0}=-4.65$ $\mathrm{kJ} \cdot \mathrm{mol}^{-1}$ and equilibrium ion exchange constant $\mathrm{K}_{\mathrm{eq}}=6.5$ confirm the hypothesis of strontium removal from soils with iron (III) cations. The effectiveness of this method is substantiated by experimental and calculated results of this study samples of radioactive soils are deactivated in $90 \%$ after 9.5 hours, the kinetic constant is $6.77 \cdot 10 \mathrm{~s}^{-1}$. The suggested method of soil cleanup with $0.2 \mathrm{M} \mathrm{Fe}^{3+}$ solutions is optimal and complies with environmental requirements.

\section{REFERENCES}

1. Bobovnikova Ts.I., Virchenko E.P., Konoplev A.V. 1990. Chemical deportments of long-lived radio- nuclides and their transformation in the soils of the Chernobyl accident area. Soil Science, 10, 20-25.

2. Bondarenko G.N., Kononenko L.V. 2001. Kinetics of $90 \mathrm{Sr}$ and $137 \mathrm{Cs}$ deportments transformation in soils. Mineralogy Journal, 3, 48-57.

3. Bulgakov A.A. 1998. Prediction methods of $90 \mathrm{Sr}$ and $137 \mathrm{Cs}$ distribution in natural soil-water systems. Extended abstract of dissertation. Vernadsky Institute of Geochemistry and Analytical Chemistry of Russian Academy of Sciences.

4. Chirkst D.E., Chaliyan K.N., Chaliyan A.G. 1994. Thermodynamics study of radioactive 137Cs soils deactivation after the Chernobyl accident. Radiochemistry, 36 (5), 459-462.

5. Chirkst D.E., Cheremisina O.V., Ivanov M.V. 2003. Thermodynamics study of iron (III) cations sorption on clay materials. JAC, 76(6), 992-925.

6. Martyushov V.V., Spirin D.A., Bazilev V.V., Fedorova T.A. 1995. The forms of radionuclides in the soils of East-Ural Radioactive Trace, Ecology, 2, 110-113.

7. Ningping L., Mason C.F. 2001. Sorption-desorption behavior of strontium-85 onto montmorillonite and silica colloids. Applied Geochemistry, 16(14), 1653-1662.

8. Rohwedder J.R., Cadore S., Abate G., Grassi M.T. 2014. Montmorillonite and vermiculite as solid phases for the preconcentration of trace elements in natural waters: Adsorption and desorption studies of As, Ba, Cu, Cd, Co, Cr, Mn, Ni, Pb, Sr, V, and Zn. Applied Clay Science, 99, 289-296.

9. Thermodynamic constants of materials: the book of references. 1981. Edited by Glushko V.P. USSR, 1-10. 